\title{
Research on Real Estate Information System of the Real Estate Market Based on Big Data Technology
}

\author{
Benli $\mathrm{Li}^{1, *}$ \\ ${ }^{1}$ Chongqing College Of Architecture And Technology, 401331
}

\begin{abstract}
This article analyzes and studies the importance of establishing a real estate information system in the real estate market. The research content of this article includes improving the efficiency of data utilization, formulating the important support of marketing strategy, and the inevitable trend of marketing system reform. The author studies the system technical route analysis, functional module design, logical hierarchical structure design, overall database design, data collection and storage method design, system key technology application, etc. The purpose of this article is to improve the applicability of information systems to regional development and to enhance the use value of big data technology itself.
\end{abstract}

\section{Introduction}

In the process of rapid social and economic development, housing as a household item for residents, its development speed is also accelerating. Affected by the previous planning, the real estate industry has a large stock at this stage. How to revitalize the city's stock assets is not only a key consideration for real estate companies under the current high pressure of land acquisition, but also one of the first problems that the local government solves to promote GDP growth. Based on the convenient conditions provided by big data technology, the establishment of a high-quality and reliable information management system is of positive significance for improving the pertinence of the marketing process and improving the efficiency of real estate marketing.

\section{The Importance of Establishing A Real Estate Information SystemI}

\subsection{Improve Data Utilization Efficiency}

Data has penetrated into various industries and their business functions, and has gradually become an important production factor. The analysis and application of massive data by real estate companies can effectively predict the growth of consumer demand and productivity, and provide basis and reference for business decisionmaking and strategy formulation. Therefore, it is very necessary to understand the characteristics of the data and process the data. Big data has four characteristics: huge data volume, various data types, low value density, and fast processing speed. From the sources of data, processing methods, and data thinking, all challenges to the reform of real estate marketing management. For the analysis of data in big data, we can realize the reference and basis for the judgment and prediction of consumer behavior in the market and the formulation of marketing strategies. This large amount of information is valuable, and this is also the basic condition for the rapid improvement of the marketing system. This is also an important means to accelerate the rapid economic development of the industry in this state.

\subsection{An Important Basis for Formulating Marketing Strategies}

Summarizing past experience in real estate sales, we can understand that in most cases, the carriers of sales activities are mainly distributed paper advertisements. In the traditional sales environment, it has good promotion value. However, with the continuous promotion of big data technology, the information content and information sources that people can obtain are also increasing. As shown in Figure 1, the number of mobile Internet users in China is currently showing a trend of rapid growth. After establishing an information management system, the existing population can be classified. It can not only provide information transmission for people with potential purchase needs, but also determine the application value of the data information itself according to the user's daily buying habits and buying behavior. This can provide reliable data support for the stable and orderly development of the economy in the information age. 


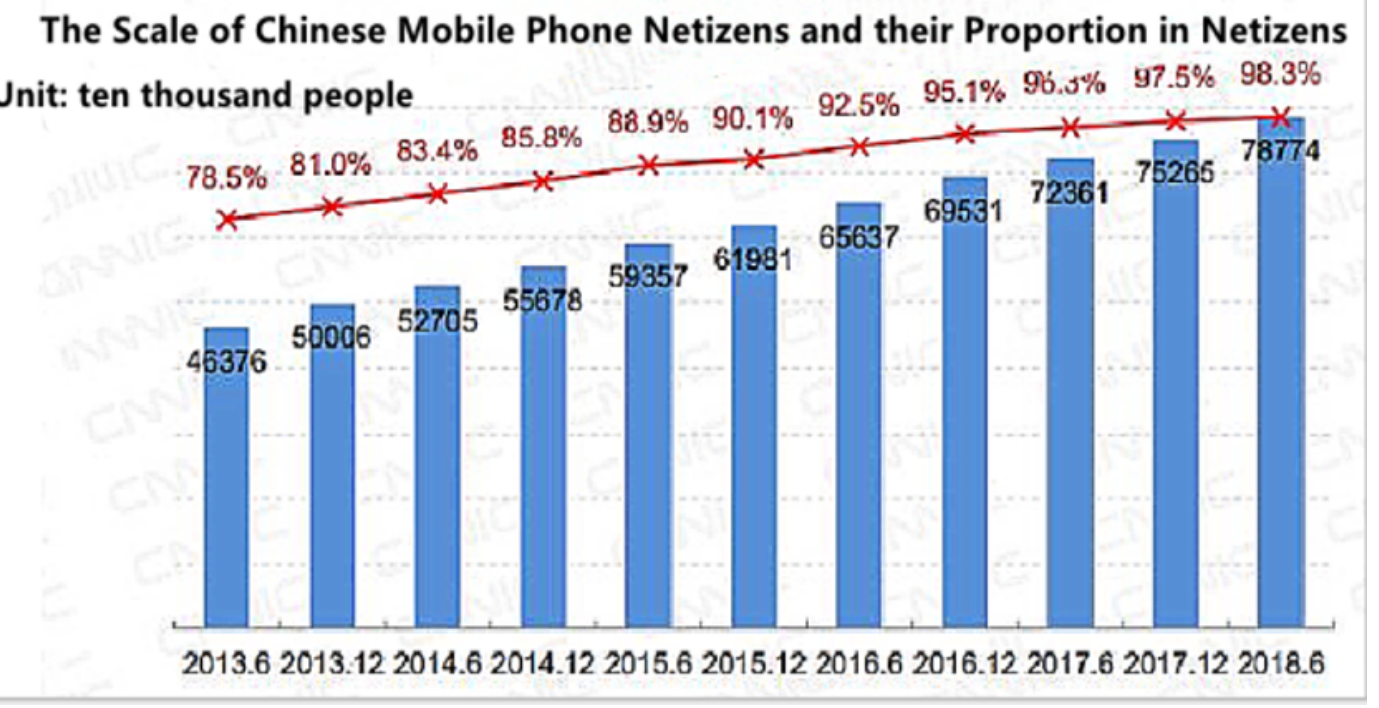

Fig1. The Scale of Chinese Mobile Phone Netizens and their Proportion in Netizens

\subsection{The Inevitable Trend of Marketing System Reform}

As shown in Table 1, according to the statistical table of China's sixth national census, in the composition of consumer groups, 20-49 years old belong to China's current main consumer group. Combined with the data information in Figure 1, China has also entered an important stage of changes in its marketing system. In the traditional real estate marketing model, the relationship between enterprises and consumers is mainly the relationship between sellers and buyers, but now their identity has given a new concept. In the real estate sales process, consumers are both participants in marketing activities and disseminators of marketing information, and their opinions will directly affect other consumers' purchases. In the context of the era of big data, real estate companies need to adjust their existing marketing ideas based on the relevant content covered in the information management system. Real estate enterprises need to find a way to help enterprises and consumers to achieve a winwin situation, so as to lay the foundation for the long-term economic development of enterprises.

Table1. Statistical Table of the Sixth National Population Census (Unit: 100 million people)

\begin{tabular}{|c|c|c|c|c|c|c|}
\hline Age & $0-19$ & $20-29$ & $30-39$ & $40-49$ & $50-59$ & $\geq 60$ \\
\hline $\begin{array}{c}\text { Number of } \\
\text { People }\end{array}$ & 3.2275 & 2.2795 & 2.1532 & 2.3015 & 1.6354 & 1.7795 \\
\hline
\end{tabular}

\section{Essentials of Building Real Estate Information System}

\subsection{System Technical Route Analysis}

\subsubsection{Operating System}

In the management process of the real estate information system of the real estate market, the selection of the operating system is a very important application content. In the specific selection process, its content includes the following parts. Firstly, in the choice of client operating systems, various real estate companies generally choose a universal Windows system. The compatibility of the system can provide customers with corresponding convenient conditions. Secondly, in the process of selecting the data server system, each real estate company can choose either the Lunix system or the Windows Server system to assist in their work. This can ensure the orderliness of the work process. Thirdly, in the choice of Web service operating system, real estate companies can choose either the Lunix system or the Windows Server system to assist their work. This can ensure the compatibility of information processing.

\subsubsection{Geographic Information System}

The help of geographic information system is indispensable in the construction of information system. Its function is to sort out the collected data and information, and also to sort out corresponding thematic graphics such as road traffic maps, surrounding landscape maps, and house layout maps. This also lays the foundation for subsequent sales. At present, the commonly used application software in the application process of geographic information system is ArcGIS software. It has the advantages of strong functionality, mature operating system, and strong convenience, which improves the reliability of the system application process. 


\subsubsection{Surveying and Mapping Information System}

Real estate is sold per square meter during the sales process, and the accuracy of graphics drawing has an important impact on the subsequent sales activities. The surveying and mapping information system commonly used in the construction of the information management system is based on Auto CAD software. The software itself not only has a strong drawing ability, but also has a very powerful graphics finishing function. The continuous integration of other new technologies at this stage also makes this technology more scalable in practical applications. This technology can successfully complete a number of tasks such as data exchange, equipment operation and management, and has extremely strong use value.

\subsubsection{Software Development Platform}

Except to the above development and application platforms, real estate companies also need to maintain the advanced nature of the system in actual applications. This also requires the system to maintain a strong advanced nature to meet the needs of use in different application states. From the actual application, the software bag development framework commonly used in specific framework applications is Microsoft. Net. In the application process of the framework, its language possesses strong versatility. It can use the corresponding universal language to complete the relevant technical content. Moreover, it also uses a complete database and Visual Studio Net to complete the establishment of the entire system during use, thereby improving the compliance of the system development process.

\subsection{Functional Module Design}

\subsubsection{Real Estate Information System}

The main work content of the establishment of the real estate information system is to collect statistics on all kinds of application data such as real estate area, real estate layout, real estate floor, real estate location, real estate price, etc., so as to lay a good application foundation for the smooth progress of the system. Judging from the current use situation, the real estate information system will use GIS software to complete the application and sorting of such information in the actual processing process. Moreover, the system also needs to dynamically manage data information during the application process. This can ensure the timeliness of the data information in the use process and meet the application requirements in different use states. For example, real estate companies use GIS software to build specific three-dimensional application models to visually display specific information, thereby enhancing the rationality of the analysis content.

\subsubsection{Development Management System}

The main content of the design process of the real estate development system includes the acquisition of land use rights, demolition schedule management, construction project planning and design, design changes, and project division and transfer. For the development enterprise, after obtaining the right to use the project, it needs to report to the superior. The content covers the basic information of the project. In the meantime, the reviewer will conduct application review after obtaining the relevant information, compare the authenticity of the information content, and wait for the information to be verified before being entered into the system for backup. Simultaneously, the enterprise will also go through the corresponding management procedures to sort out the construction progress. In addition, in the development process, the company also needs to strengthen the tracking management of the project content and update the system content in time. This can ensure the compliance and reliability of the entire system application process [1].

\subsubsection{Transaction Management System}

Except to the above application systems, real estate companies also need to use transaction management systems to assist in the smooth progress of related work. In the application process of the transaction management system, its main application function is to perform transaction registration, basic information query, information screening and transaction billing management for real estate in transaction status, so as to ensure the orderliness of the data transaction process. In the development of real estate market transaction activities, its basic data can lay a good application foundation for the smooth progress of real estate development. Besides, real estate companies can also use the management system to directly publish relevant information about existing real estate to help users better understand the current management situation. With the help of statistical analysis methods, the aggregated data information is summarized, and the comprehensive processing of various application management data can better meet the market service requirements. In this way, the market development behavior can also be adjusted to improve the reliability of the management process. In addition, in specific application management, the system is also responsible for housing information interaction, transaction management, and transaction process review. This can meet the requirements of comprehensive management in different states [2].

\subsection{Logical Hierarchy Design}

In the design process of this structure, its content includes the following several layers of application structure. Firstly, the presentation layer. This level belongs to the outermost layer of the entire application structure, and it is an important carrier for information interaction with users. The main work content of this level in the application process is to feedback and receive user request data. At the same time, it can also provide users with a more reliable information interactive operation interface, and improve users' service satisfaction using this structure. 
Secondly, the business logic layer. This level belongs to the core part of value in the entire application system. It is between the data access layer and the system presentation layer of the system, and plays a role in linking the two. In the specific work links at this level, the main work content is to sort out the existing business content regulations and related business service processes. In the meantime, it can use the demand structure to complete the application design of the entire system, thereby providing high-quality and reliable service content. Third, the data access layer. The main work content of this level in the application is to access the data information, at this time it can access the database. Meanwhile, it can compile application documents to ensure the reliability and practicality of the entire application level. In the process of establishing this level, big data technology was used to summarize the information content. Moreover, this level pays attention to application information collation during the management period, and has a good application effect [3].

\subsection{Overall Database Design}

In the construction of the information management system, completing the database construction is a very important application content. Combining the existing basic real estate data, the information management system can establish a GIS database, a real estate property rights management database, a real estate surveying and mapping information collation database, and on-site reallife images in the actual application process. Moreover, real estate companies can also optimize management of these established databases on the basis of the data warehouse, and establish reasonable logical application relationships. In this way, it can form a stable data sharing platform, store and manage data information uniformly, and meet established application requirements. During the application of database data, the total amount of information stored in the system is relatively large. At this time, the system needs to rely on the high operating capability of big data technology to adjust the operating speed of the system based on the logical relationship between the data. Otherwise, according to the actual situation in the application stage, a temporary database can be established during the database establishment process. In this way, these subsystem databases can not only be integrated together for comprehensive management, but the system can also summarize the contents of various databases in the process of business processing. In the data application stage, the staff also need to pay attention to the keyword matching degree design to meet the basic requirements of fast data retrieval [4].

\subsection{Data Collection and Storage Method Design}

The following aspects should be paid attention to in the application design of data collection and storage methods. (1) Data entry processing. Enterprises need to use the application functions of the system to store the currently used data information such as real estate property rights information and tracking business data in the corresponding database. Moreover, the system can directly enter the scanned image data into the virtual archive, so that it can form a good matching relationship with the virtual archive to facilitate the smooth development of various tasks. (2) Utilization of basic data information. Companies can use big data technology to organize the application data. In the actual processing process, companies need to take into account the application of basic framing. In most cases, the drawing ratio of the graphics is 1:500. The system can use GPS surveying and mapping technology and total station surveying and mapping technology to assist related data collection and improve the reliability of data collection results. It should be noted that the spatial data involved in the system content needs to use spatial calculation methods to complete the information accuracy check, so as to ensure the reliability of the data analysis results. (3) The system can transform the original data. The system can import the required data again on the basis of the existing real estate data. Moreover, in this process, the enterprise also needs to process the corresponding data. Enterprises can use existing conversion tools to complete the overall processing of data information based on the platform application structure, and enter it into the corresponding database to improve the reliability of analysis results. (4) The system can perform hierarchical association with existing data information. For example, to effectively associate the existing attribute data in the system with the corresponding spatial data. This can effectively improve the access efficiency of data information in practical applications. Simultaneously, allocating data to the corresponding database can lay the foundation for the subsequent data application process [5].

\subsection{System Key Technology Application}

Many key technologies will be used in the establishment of the system, and the specific application classification includes the following points. Firstly, GIS technology and big data technology are the basic conditions in the system construction process. Secondly, workflow technology. As an application service, this technology involves interactive processing between work in the actual application process, so that the overall system can be in a stable operation state. In application, this technology mainly involves two aspects of "construction" and "operation". It can perform data query based on the basic requirements put forward by users, and has strong application value. Thirdly, data exchange technology. The main function of this technology is to enhance the current sharing of application data and establish an effective platform for information communication between various departments. In the meantime, it can also be compatible with remote systems, which can expand the coverage area of real estate information and improve the application effect of the basic platform. Fourth, SOA technology, that is, serviceoriented architecture. This structure is a component model with strong applicability in the application process, which can effectively associate the corresponding content in different service processes. This also makes the services have a good relationship to meet the interactive processing of different application information [6]. 


\section{Conclusion}

In summary, in the process of real estate development and management, the establishment of an information application system has good use value. Real estate companies need to make full use of the application advantages brought by big data technology at this stage and integrate it into the information management system. For one thing, this allows data information to be correlated to improve the application value of potential data. For another, this also has positive significance for improving the practicality of real estate marketing strategies.

\section{References}

1. Li Qingqi. Analysis of Loudi Real Estate Information System Based on Big Data Technology[J]. Management and Technology of Small and Mediumsized Enterprises (Late Edition), 2020(10): 156-157.

2. Chen Yuxin. Design and Implementation of Quanzhou Real Estate Information Management System[J]. Geoinformation of Surveying and Mapping, 2019, 39(06): 74-76+79.

3. Zeng Jie, He Shu. Design and development of Ganzhou real estate information system based on GIS[J]. Surveying and Spatial Geographic Information, 2019, 37(03): 107-110+113.

4. Wang Ying. Research on the Construction of "Real Estate Information System" in Suzhou City[J]. Fujian Computer, 2018, 27(11): 60-61+47.

5. Lin Yaohua, Zhu Kunzi, Chen Jing. Development of Putian City Real Estate Information System Based on WEB GIS [J]. Journal of Xinxiang University (Natural Science Edition), 2018, 26(03): 63-65.

6. 2006 Geographic Information System Excellent Project Silver Award Project Dalian Real Estate Fundamental Geographic Information System [J]. Geographic Information World, 2017(03): 88-89.

7. Li Hongkui, Chen Hongyan. Design and construction of Dalian real estate basic geographic information system [C]. Chinese Society of Surveying and Mapping, 2017: 402-410. 